\title{
Micro-optical structures for daylighting and led systems ${ }^{\star}$
}

\author{
Helmut F.O. Mueller ${ }^{*}$ \\ Green Building Research \& Development GmbH, Oberkasseler Str. 6, 40545 Duesseldorf, Germany
}

Received: 8 February 2017 / Received in final form: 2 July 2017 / Accepted: 27 July 2017

\begin{abstract}
Different micro-optical structures have been developed for the application in transparent building elements like windows or glazed partitions. In cooperation with the Department of Microstructure Technology, TU Dortmund, as well as partners from research institutions and industry solutions for the following two tasks were elaborated: (1) two-sided structures on glass panes for redirection of direct sunlight into the depth of rooms improving daylighting; and (2) one-sided structures on clear panes, edge-lit by LED, for one-way and selective light emission. High demands were made on the small structures $(50-200 \mu \mathrm{m})$ as to efficiency of light redirection respectively light emission, and quality of image. Technologies for large scale manufacturing are developed in cooperation with partners from industry. Having tested laboratory samples $(100 \mathrm{~mm} \times 100 \mathrm{~mm})$ successfully, larger prototypes are produced in hot embossing and UV embossing technique. Optimization of structure geometry and manufacturing process is continuing while design solutions for component and luminaire integration are developed. Architectural applications in transparent building elements for combined natural and artificial lighting are demonstrated, achieving high quality and low energy room illumination.
\end{abstract}

\section{Introduction, state of the art}

"Micro-optical structures" are generally defined as surface structures with lateral and depth dimensions in the order of 1-1000 $\mu \mathrm{m}$. They are applied in transparent building elements for advanced daylighting as well artificial lighting systems in order to improve quality as well as energy and cost efficiency of lighting.

Figure 1 shows the principle solution of sunlight redirection to the depth of the room and a double-sided microstructure for this application [1]. The specific shape of the structures redirects incident light from a solar altitude range between $15^{\circ}$ and $65^{\circ}$ to emergent angles larger than $0^{\circ}$ (to the ceiling) without solar tracking.

Figure 2 shows the integration of LED lighting in windows. The angle-selective light emission by the cylindrical microstructure allows to look through the lightguide and the window unless you do not look directly into the emitted light.

The initial development of suitable micro-optics for the described applications in Figures 1 and 2 by simulation, manufacturing of prototypes and measurements is proceeding now in a joint development project with a run-time

\footnotetext{
^ Paper presented at: World Renewable Energy Congress XVI, 5-9 February 2017, Murdoch University, Perth, Australia (MicroOptical Structures for Daylighting and LED Systems).

* e-mail: helmut.mueller@greenbuilding-rd.com
}

from 2016 to 2019. Scientists, manufacturers of microstructures and building components as well as architects are co-operating in the integrated approach of the TALED project (see "Acknowledgements" section).

\subsection{Objectives}

The main objectives and work packages of the project are defined as follows. The present state microstructures have to be optimized as to optical performance and largescale manufacturing. The technical integration of micro-structured daylighting and LED systems in windows is developed in a systematic approach of modular systems. Prototypes of lighting systems in realistic dimensions and constructions are manufactured and their performance is measured in laboratories and test rooms. Last but not least, the options of architectural integration are demonstrated in exemplary designs, complemented by simulations of lighting performance and energy efficiency.

\section{Methodology and results}

\subsection{Optimization of structures and manufacturing technology}

The optimization of micro-optical structures concerns system performance and largescale manufacturing technologies. Experienced project partners are involved for the two the different technologies: hot embossing (Fig. 3) and UV embossing (Fig. 4). 

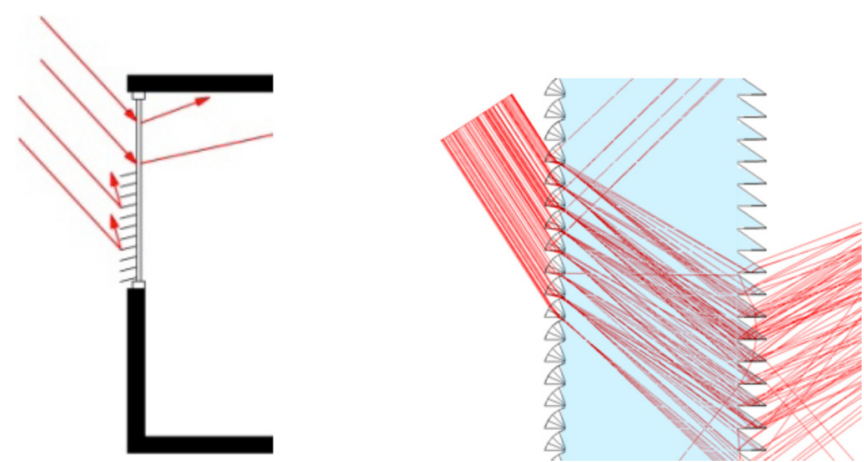

Fig. 1. Left: Window with sunlight redirecting glass in upper window area and shading in lower window area. Right: Doublesided microstructure with lenses and prisms for redirection of sunlight.
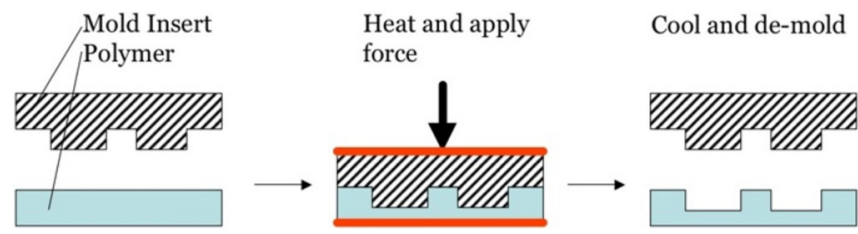

Fig. 3. Hot embossing.
LED

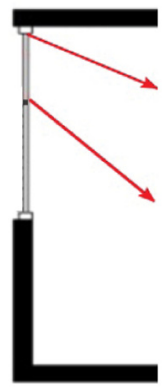

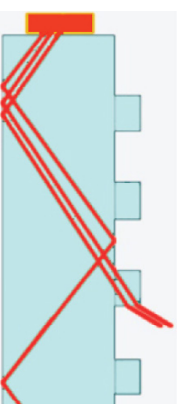

Fig. 2. Left: Window with LED lighting in upper window area by transparent lightguide. Right: Edge-lit lightguide with cylindrical microstructure for one-sided, selective light emission $[2,3]$.

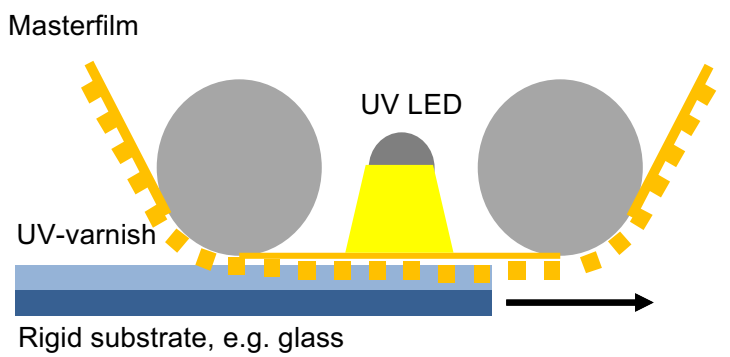

Fig. 4. UV embossing.

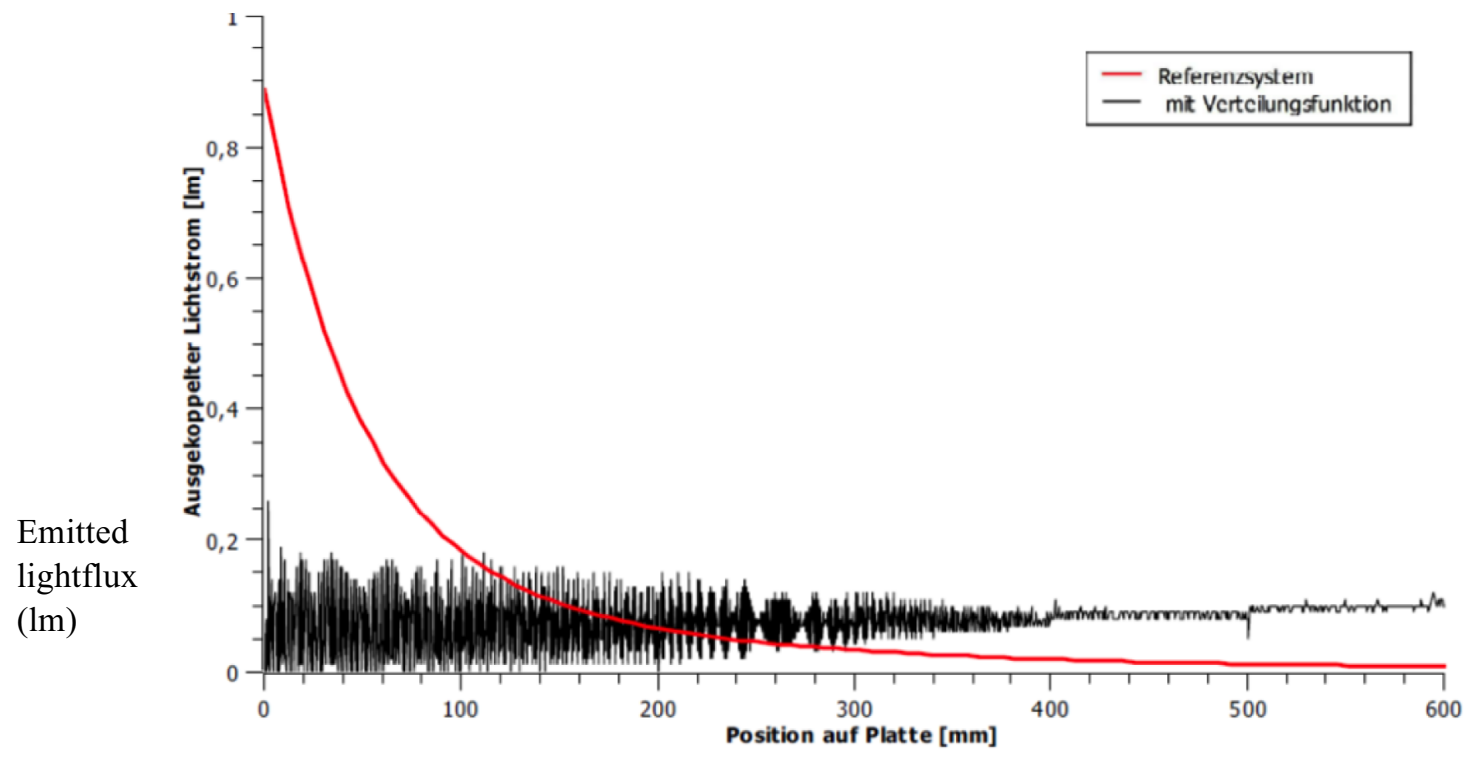

Position on light guide ( $\mathrm{mm})$

Fig. 5. Optimized light emission over the length of lightguide by distribution function of structure. Red line: Reference system with even distribution of structure. Black line: System with distribution function ([4], RIF).

Hot embossing is applied for one-sided as well as for two-sided polymer structures in one step. Structure dimensions are $200-500 \mu \mathrm{m}$, produced in maximum element sizes of $1500 \mathrm{~mm} \times 600 \mathrm{~mm}$. The master is a flat mould cut in steel or brass (for prototypes) by flywheel or fad. Manufacturing is carried out in a plate to plate process in PMMA and PDMS. The de-moulding of the hot embossing process required an adaption of structure geometries.

UV embossing is applied for one-sided as well as for double-sided polymer structures. Structure dimensions are $20-500 \mu \mathrm{m}$, produced in a maximum element width of 

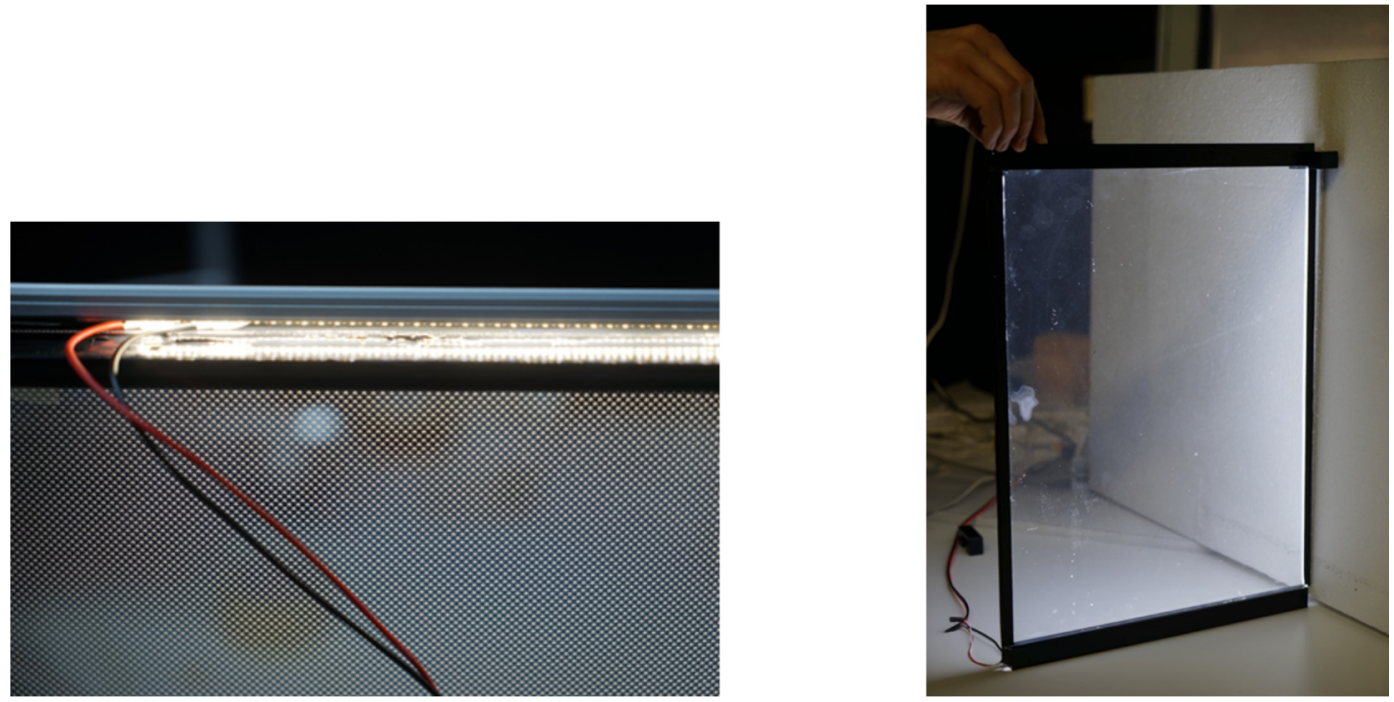

Fig. 6. Prototypes of LED light guides in hot embossing (left) and UV embossing technology (right).

\begin{tabular}{|l|l|l|l|}
\hline \multirow{2}{*}{$\begin{array}{l}\text { Lighting } \\
\text { System }\end{array}$} & \multicolumn{3}{|l|}{ Glazing } \\
\cline { 2 - 4 } $\begin{array}{l}\text { Sunlight } \\
\text { redirection } \\
\text { (SL) }\end{array}$ & 3 panes \\
\hline $\begin{array}{l}\text { LED- } \\
\text { Lightguides } \\
\text { (LG) }\end{array}$ & 4: Micorprisms & \\
\hline
\end{tabular}

Fig. 7. Integration of microstructures for sunlight redirection and lightguides in double and triple glass units.

$1000 \mathrm{~mm}$. The master is produced by photolithographic technology on a cylindric metal mould or on a film. Manufacturing is carried out in a roll to plate or roll to roll process in varnish which is hardened by UV light. The substrate can be glass or PMMA.

For the LED lightguides two options of light emission were examined: even or uneven light emission depending on the distribution of structural elements in relation to the light source. Figure 5 shows that the reference system with regular distribution leads to a high emission of the light flux on the first $100 \mathrm{~mm}$ of the light guide. By a specific stochastic distribution of the structure a uniform light emission over the length of the lightguide is achieved.

Simulations of the illuminance of an office room have shown, that the uniformity of light emission from the lightguide has no significant influence on the illuminance distribution in the room. 

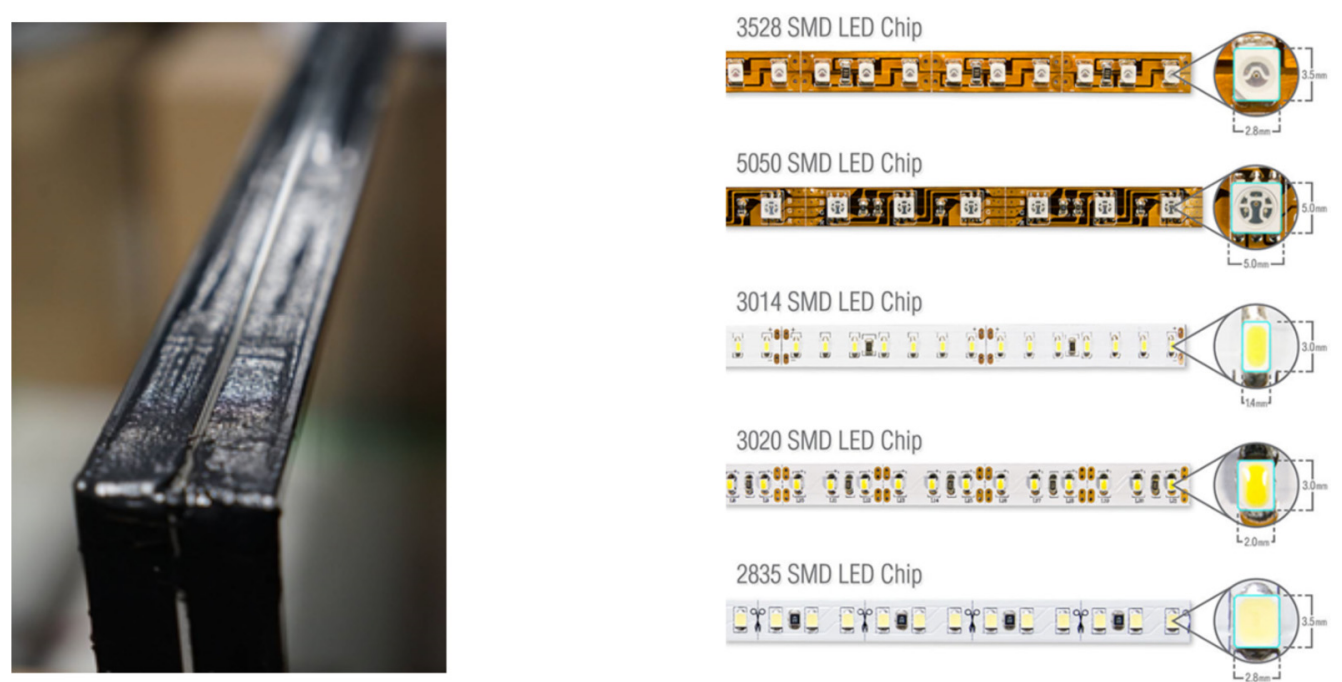

Fig. 8. Triple glazing with light guide in the middle (left) and fitting LED strips with differing LED dimensions (right).
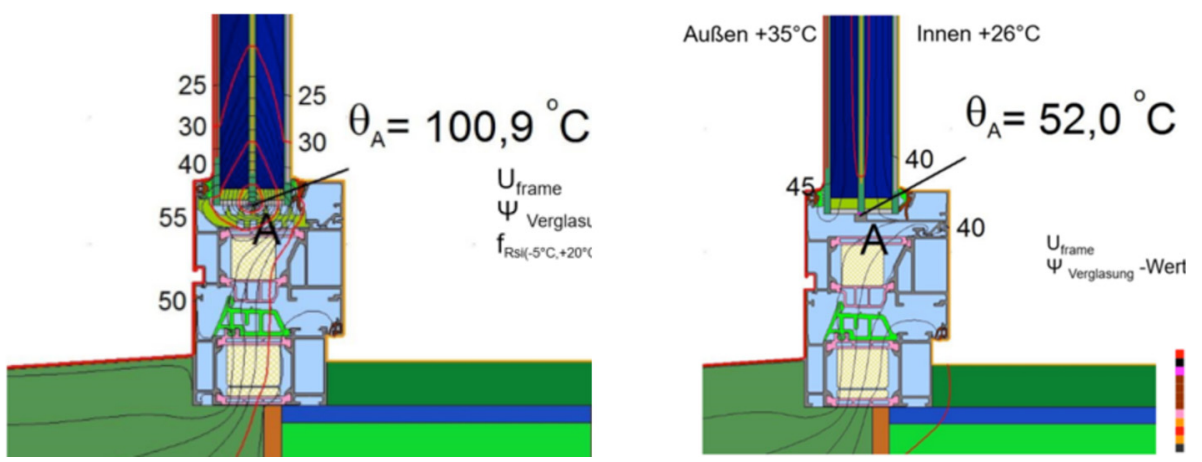

Fig. 9. Temperature in window frame with LED $(20 \mathrm{~W} / \mathrm{m})$ mounted on edge of lightguide. Left: Well insulated frame without heat conduction. Right: Heat conduction by metal connection from LED's to the room facing surface of the frame ([4], ai3).

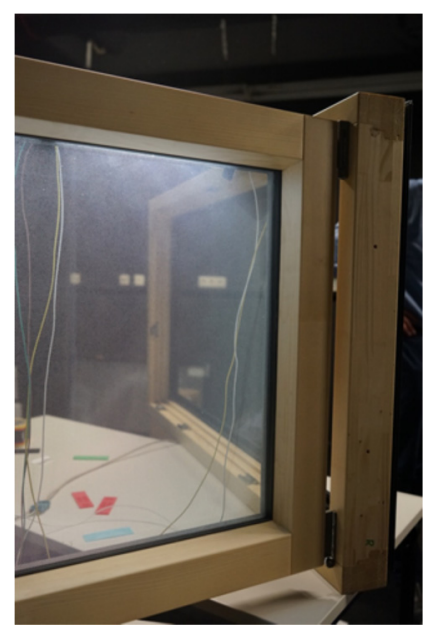

Fig. 10. LED lighting integrated in a timber window frame. Laboratory mock-up.

The optimization of LED lighting included the examination of shape and thickness of lightguides. Findings are: the thinner the light guide, the higher the emitted light flux. A wedge-shaped lightguide increases the emitted light flux. In consideration of construction and available material $2 \mathrm{~mm}$ thick.

PMMA panes with parallel surfaces were chosen as light guides. Actual prototypes of the LED lightguides show a higher transparency for the samples produced in UV embossing (Fig. 6).

\subsection{Building integration}

The microstructures are protected against physical impact and atmospheric deposits by positioning them in the void between two glass panes. The variation of glass integration in Figure 7 shows solutions for double and triple glazing. The two-sided structure for sunlight redirection can be integrated either on a third glass pane or as a composite film on one of the void surfaces of a double glass unit. The one-sided structure of LED lightguides can be positioned on surface 2 of a double glass unit, if surface 1 is kept clean. A third pane has to be installed, if the risk of light emission by dust on surface 1 has to be eliminated. The combination of microstructures for both, sunlight redirection and LED light guides, can only be realized in a triple glass unit, using a composite film for sunlight redirection. 

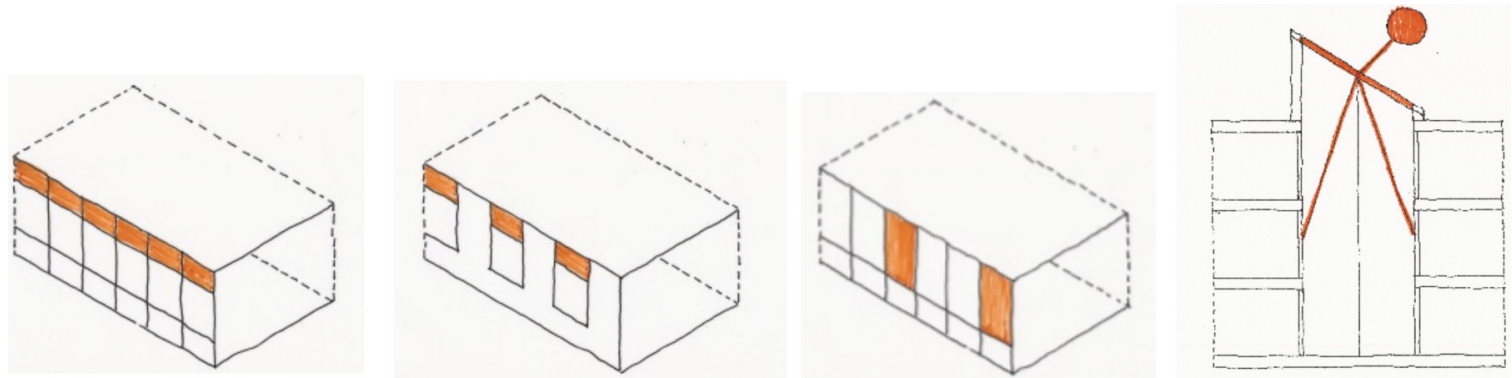

Fig. 11. Architectural integration of sunlight directing elements.

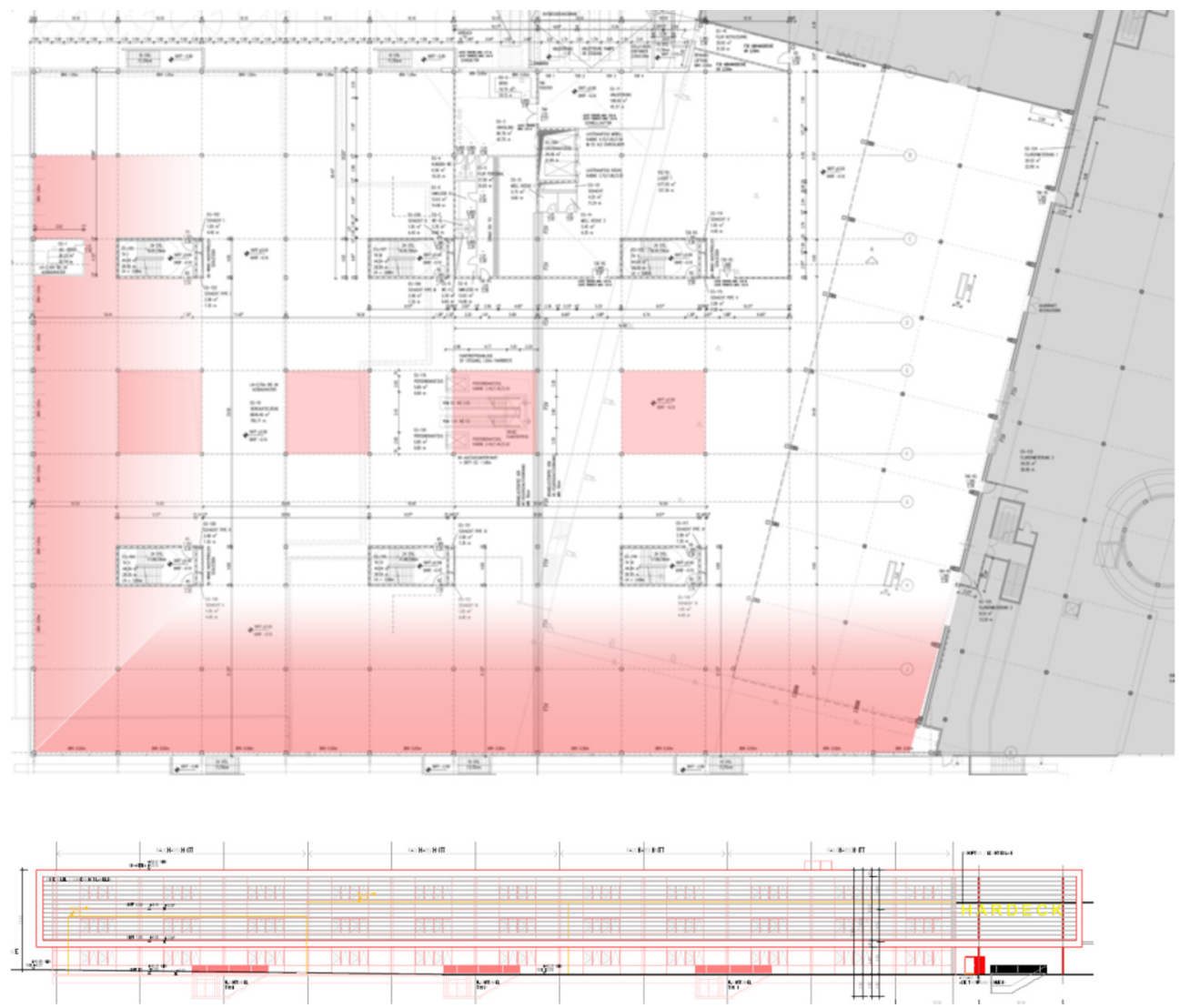

Fig. 12. Example for sunlight redirection in a shopping center. Daylit floor areas red.

For the LED lighting $2 \mathrm{~mm}$ lightguides were integrated in a double glass unit. Fitting LED, mounted on strips, are fixed on the edge of the lightguide. There is a variety of LED on the market, offering the necessary light flux of approximately $3000 \mathrm{~lm} / \mathrm{m}$ (Fig. 8).

Integrating LED's in window frames means to control the heat emitted. Simulations and tests have shown, that LED with $20 \mathrm{~W} / \mathrm{m}(3000 \mathrm{~lm} / \mathrm{m})$ can create temperatures $>100^{\circ} \mathrm{C}$ in a well insulated window frame (Fig. 9). By special means of heat conduction from the LED to the outer shell of the frame temperatures can be reduced to acceptable values $<60^{\circ} \mathrm{C}$. Tests with aluminium and timber frames have bee carried out (Fig. 10).

The construction details of integrating LED's in windows are solved in co-operation with the involved manufacturers of glass, luminaires and facades. A special challenge is the accurate positioning of LED's on the edge of the light guide in the glazing unit, which has to work under conditions of initial mounting as well as maintenance. A sample is shown in Figure 10.

\subsection{Architecture and building types}

The application of daylighting and LED systems with microstructures is strongly influenced by architecture and building type. The position and size of sunlight redirecting elements in facades are influenced by the depth and height of rooms to be illuminated naturally. Specific solutions are offered for atria, courtyards and lightshafts to be illuminated from skylight by redirected sunlight (Figs. 11 and 12). 

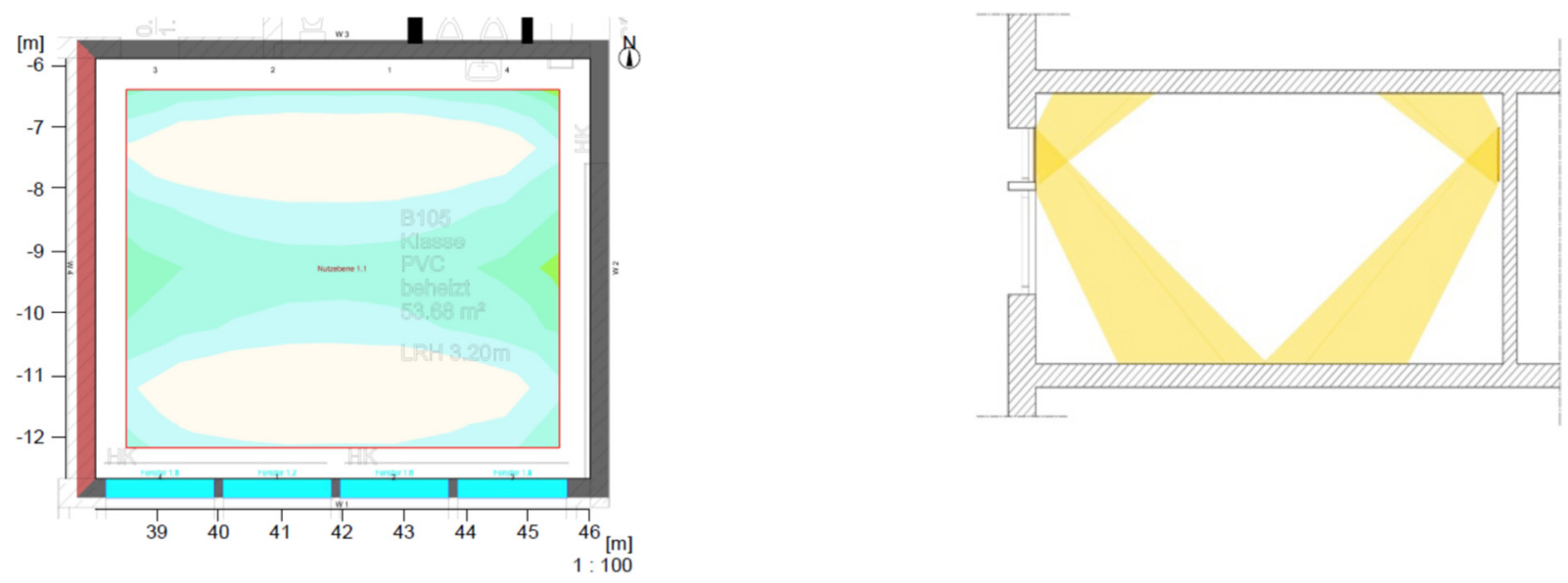

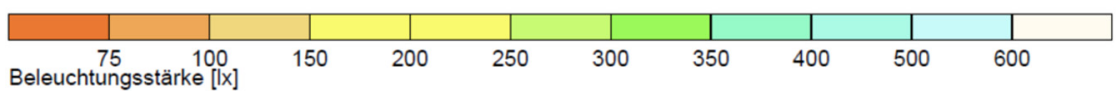

Fig. 13. Example of a classroom illuminated by LED lightguides in facade and partition.
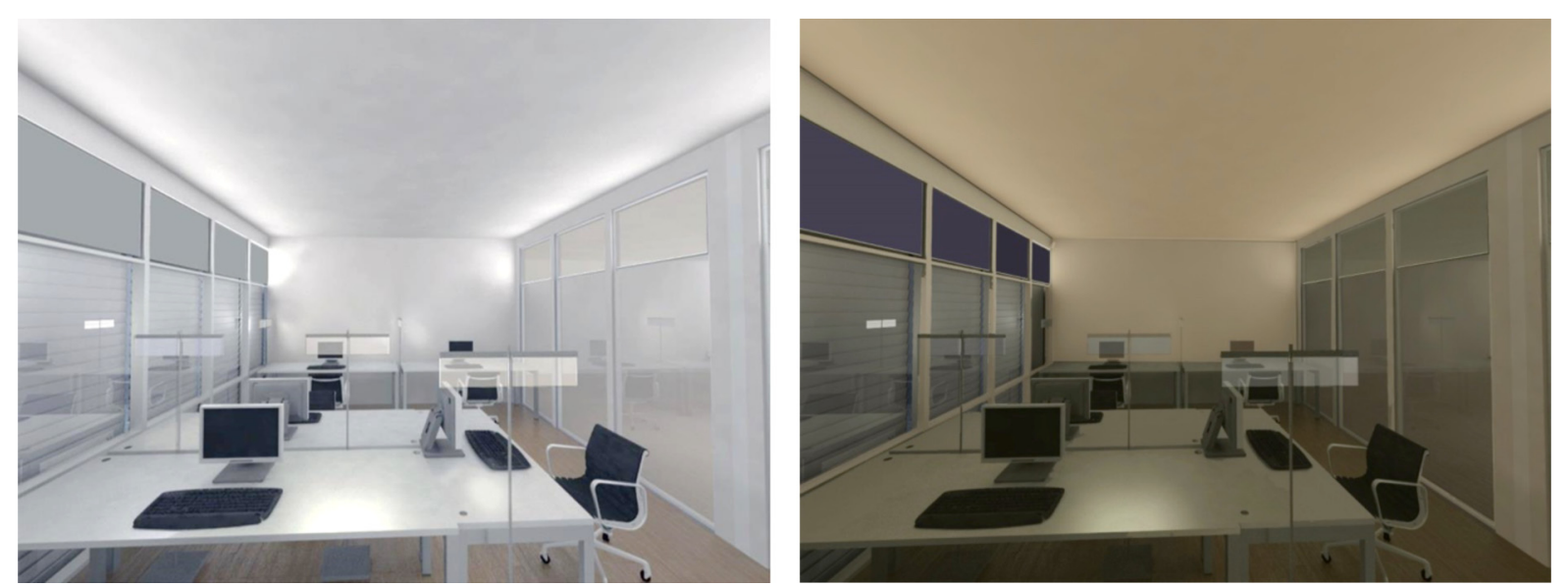

Fig. 14. Office room with LED lightguides in upper areas of windows and partitions and in task lights. Left: Cool white, high illuminance (activity support, e.g. in early morning). Right: Warm white, low illuminance (activity reduction, e.g. in late afternoon).

For the integration of LED lightguides in transparent buildings components like windows, partitions and roof lights typical rooms and buildings are analysed.

Actual designs for different kinds of buildings are used in co-operation with architects to check the applicability of the lighting systems with microstructures and to adjust them to the specific situation. Based on systematic siumulations and measurements in test rooms, thumb rules for dimensioning are developed for both, sunligthing and LED lighting systems.

Figure 13 shows the example of a classroom illuminated by LED lightguides in facade a partitition. Room dimensions (length $\times$ width $\times$ height) are $8 \mathrm{~m} \times 7 \mathrm{~m} \times 3 \mathrm{~m}$. The technical lighting data are:

Two lightguides (window and partition) with 2 LEDstrips each $3000 \mathrm{~lm} / \mathrm{m}$; room depth $7 \mathrm{~m}$.

Overall light flux $2 \times 2 \times 3000 \mathrm{~lm} / \mathrm{m} / 7 \mathrm{~m}=1714 \mathrm{~lm} / \mathrm{m}^{2}$.

Mean illumination $500 \mathrm{~lx}$.

Room utilization factor (overall efficiency) $500 \mathrm{~lm} / \mathrm{m}^{2} /$ $1714 \mathrm{~lm} / \mathrm{m}^{2}=0.29$.
Installed wattage $1714 \mathrm{~lm} / \mathrm{m}^{2} / 150 \mathrm{~lm} / \mathrm{W}=11 \mathrm{~W} / \mathrm{m}^{2}$. The LED lighting offers a variation of illuminance and colour temperature [5]. Thus it allows to adjust the illumination to the biorhythm and activity level of the occupants, as Figure 14 shows. Lightguides with LED at the upper and lower edges are positioned in the clearstoreys of windows and partitions. In addition desk lights with transparent lightguides are distributd in the room.

\section{Conclusions}

Micro-optical structures are used for advanced daylighting and LED systems, which can be integrated in transparent building elements of facades and partitions as well as in roof lights. Large scale manufacturing of the structures is applied and the first prototypes have been integrated in glass- and window constructions. The combination of both systems will increase the lighting comfort and the energy efficiency in non-residential 
Table 1. Participants of the joint research project TALED with matter of collaboration, name and logo of participant.

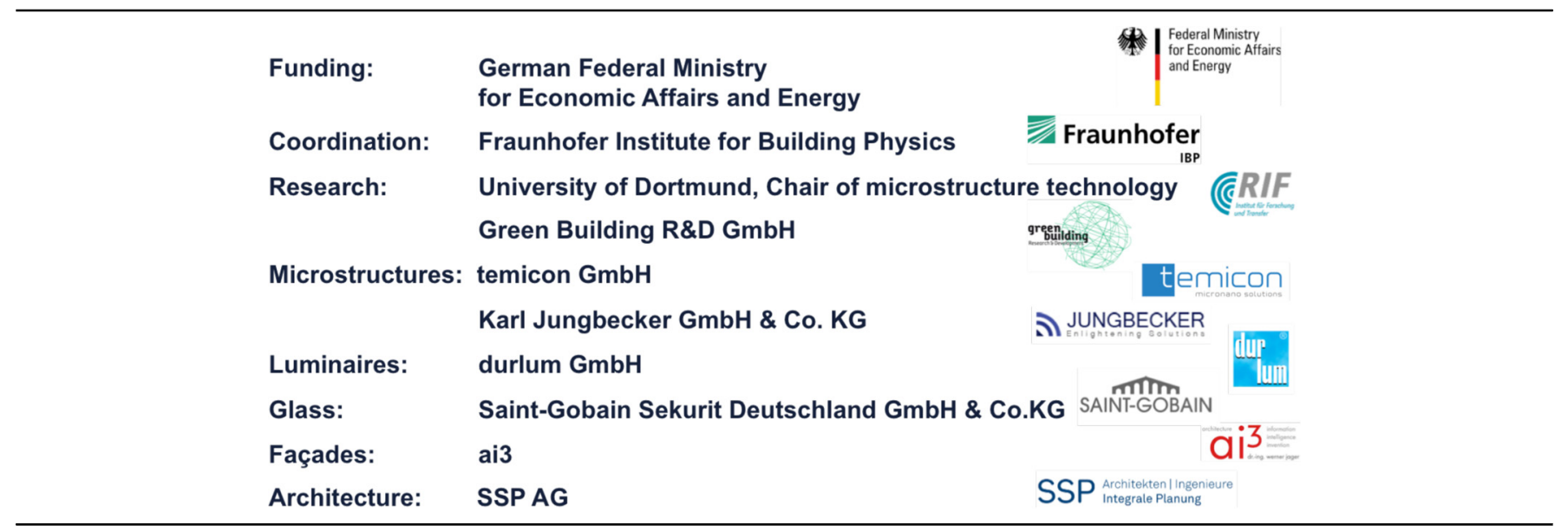

buildings. The next steps towards marketable products will be to apply and monitor the systems in test rooms and demonstration buildings.

The participants of the joint research project TALED, duration from 2016 to 2019, are shown in Table 1.

\section{References}

1. S. Klammt, H.F.O. Müller, A. Neyer, Microoptics for efficient redirection of sunlight, Appl. Opt. 51, 2051 (2012)

2. F.-C. Tengler, M. Jakubowski, A. Neyer, High Transparent Light Guiding Plate for Single-Sided Light Emission, Poster Abstract, Micro and Nano Engineering (MNE), London, 2013
3. H.F.O. Mueller, F. Sasso, Energy-efficient lighting by LED, in Proceedings WREC XIII, 03-08 August (University of Kingston, UK, 2014)

4. Research Reports of Project TALED, Energy- and cost efficient, façade integrated Day- and LED lighting based on mico-optical components (2016-2019) (unpublished), Coordination: Fraunhofer Institute Building Physics, Stuttgart, Germany (2016-2019), Partners: RIF e.V., Karl Jungbecker GmbH, Temicon GmbH, Durlum GmbH, Saint-Gobain Securit GmbH, Green Building R\&D GmbH, ai3, SSP AG, Funding: German Federal Ministry for Economic Affairs and Energy

5. H.F.O. Muller, Spectral variation of energy-efficient room lighting, in Proceedings Med Green Forum \& Renewable Energy, edited by A. Sayigh (Springer, Switzerland, 2017), pp. 755-765, ISBN 978-3-319-30745-9

Cite this article as: Helmut F.O. Mueller, Micro-optical structures for daylighting and led systems, Renew. Energy Environ. Sustain. 2, 29 (2017) 